\title{
Monitoring System of tourist traffic (MSTT) for tourists monitoring in mid-mountain national park, SW Poland
}

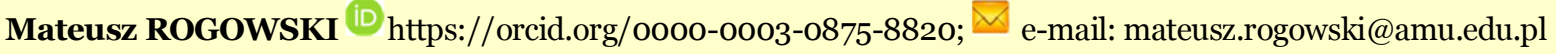 \\ Department of Tourism and Recreation, Faculty of Geographical and Geological Sciences, Adam Mickiewicz University, \\ Bogumita Krygowskiego 10, 61-68o Poznań, Poland
}

Citation: Rogowski M (2020) Monitoring System of tourist traffic (MSTT) for tourists monitoring in mid-mountain national park, SW Poland. Journal of Mountain Science 17(8). https://doi.org/10.1007/s11629-019-5965-y

(C) The Author(s) 2020.

\begin{abstract}
National parks are highly valuable natural areas and have the potential to attract a large number of visitors. The number of visitors at national parks is systematically increasing, often exceeding Tourism Carrying Capacity (TCC) of trails. This situation requires adjusting the number of park visitors to adapt to sustainable management systems of visitor flow, thus preventing or counteracting overtourism. The aim of the study is to propose a comprehensive method for tourists monitoring in mid-mountain national park presented on the example of the Stołowe Mountains National Park (SMNP) in Poland, called as Monitoring System of tourist traffic (MSTT). The study describes six stages procedure of tourists Monitoring System creation and application as an optimal measurement technique. The MSTT enabled a multidimensional analysis of tourist traffic in SMNP. With the help of 39 pyroelectric sensors and surveys data spatio-temporal characteristic of visitor flow was obtained. The data generated in MSTT included hourly, daily, weekly, monthly, and annual reports, taking into account the direction of traffic measuring both directions: entries (IN), exits (OUT) and passages (IN+OUT). The results from pyroelectric sensors were supplemented with field surveys, where visitor's motivations, preferences, and behaviours were determined. In 2017 a total of 871,344 visitors were recorded in SMNP what causes one of the most popular national parks in Poland. The SMNP is a suitable destination for short breaks leisure visits in wilderness. In order to sustain MSTT methodology in the long-run the set of guidelines together with the workload estimates were presented. In the future, the
\end{abstract}

Received: 30-Dec-2019

Revised: 05-May-2020

Accepted: 23-Jun-2020
MSTT can be further developed, including monitoring of climbing, cycling, cross-country skiing, car traffic and illegal tourism assessment. The MSTT can be considered as a useful tool for tourism management in mid-mountain national parks throughout the entire calendar year.

Keywords: Tourist traffic; Visitor flow; Pyroelectric sensors; Eco-Counter; Hiking; Stołowe Mts. National Park

\section{Introduction}

National parks are highly valuable natural areas and they have the potential to attract a large number of visitors ${ }^{1}$. The establishment of a national park is considered to be a major asset to its local area (e.g., Stasiak 2007) and motivates visitors to come. The number of visitors to national parks is systematically increasing in Poland, which is prompted not only by the desire to visit the wilderness and pursue environmental experiences, but also by the need to relax and practice outdoor sports (Kruczek and Przybyło-Kisielewska 2018). The main effect of these activities is an increase in number of visitors, which has exceeded capacity of trails in some national parks at this point. This issue of "overtourism" in national parks is the subject of study in many papers (Menzione 2018). This situation requires such a large number of visitors to adapt to sustainable management

\footnotetext{
${ }^{1}$ In this paper the word "visitor" means number of peoples who visited in study area and its behavior describing
} 


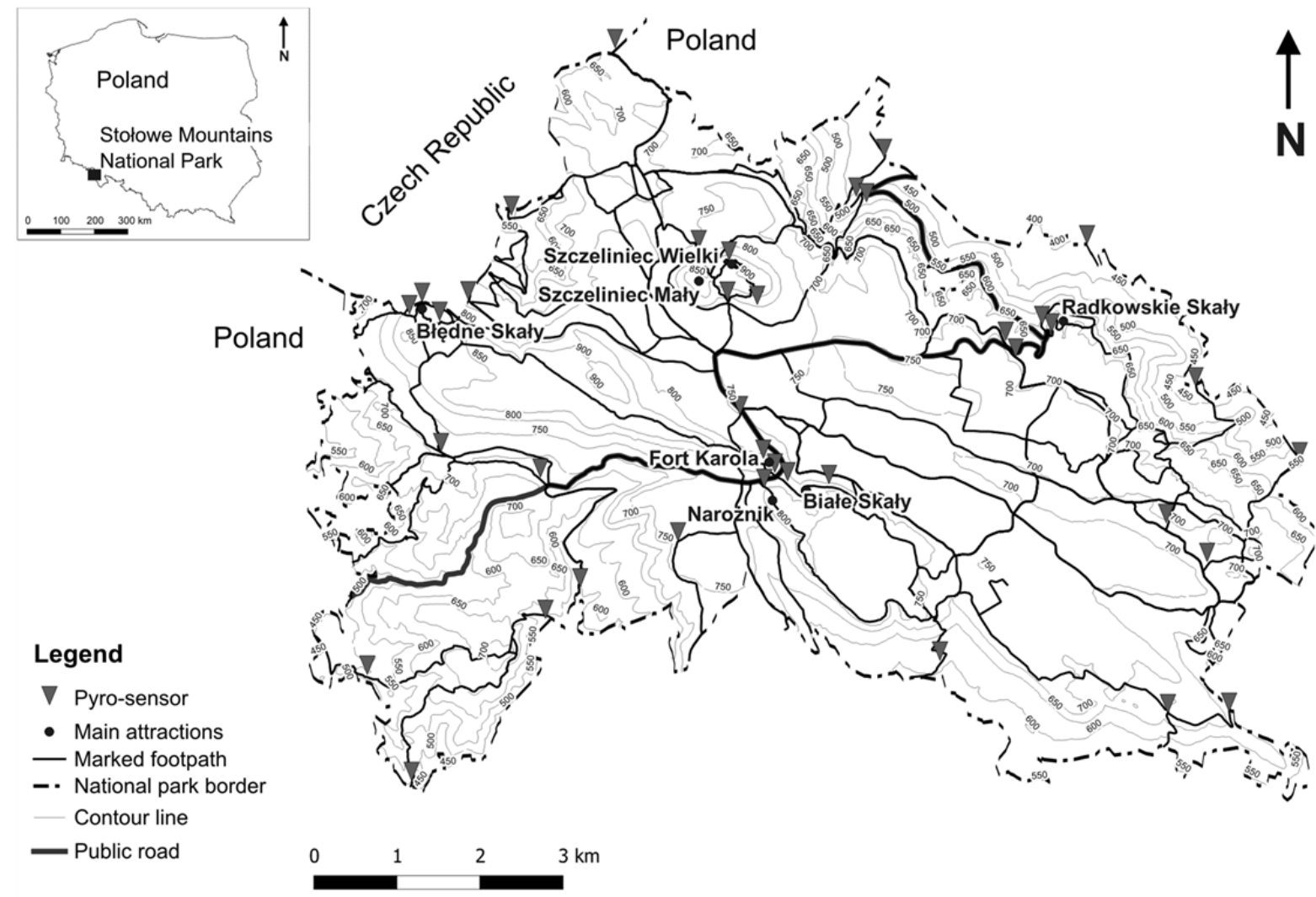

Figure 1 Location of pyroelectric sensors in Stołowe Mts. National Park in the Sudety Mountains in south-western Poland.

systems of visitor flow. To achieve this, it is important to assess the size, variability, and behaviour of visitors using an effective visitor monitoring systems in a national park.

The monitoring of tourist ${ }^{2}$ traffic volume is carried out by examining traffic at attractions, on tourist trails and in specific geographic areas. Area monitoring is the most difficult undertaking in terms of planning, formulation, and implementation of tools and requires a multidimensional approach. Monitoring in national parks is needed to monitor not only the natural environment, but also tourist traffic. Monitoring can help assess the spatial distribution of visitors, routes of their movement, most frequently visited places, time spent in the park, as well as the preferences and geographic origin of tourists. This should serve to highlight the relationship between visitors, their interests and the specific area that meets their expectations to the fullest extent possible (Rogowski 2018a).

This study aims to propose a comprehensive

${ }^{2}$ In this paper the word "tourist" means general of tourism phenomenon in study area. method for tourists monitoring in mid-mountain national park presented on the example of the Stołowe Mountains National Park (SMNP) in Poland, called as Monitoring System of tourist traffic (MSTT). The main focus is to determine the procedure for tourists monitoring system development, system creation and application as an optimal measurement technique. In addition, the MSTT data allowed for spatio-temporal characteristic of visitor flow in SMNP.

The issue of monitoring of tourist traffic is important in the management of natural protected areas and the planning of sustainable tourism. Initial research in the form of handbooks described the purpose and means of the monitoring of tourist traffic by way of visitor counting, visitor surveys, and reporting and interpretation of results (Kajala et al. 2000; Watson et al. 2000) in order to understand visitor motivations, preferences, and behaviour (Beunen et al. 2008; Konu and Kalaja 2012; Geoffrey et al. 2019). Furthermore there exist other types of visitor groups - especially in mountain areas: conservationist casual, contemplative, and active adventure visitors 
(Farias Torbidoni et al. 2005); nature minded, sports-oriented and general-purpose hikers (Farias Torbidoni 2011). Yet other studies focus on determining the natural landscape preferences of visitors (De Lucio and Mubica 1994) and the experiences of visitors (Chhetri et al. 2004).

An important issue is the monitoring of visitors flow in national parks (Cessford and Muhar 2003) in order to determine priorities in national park tourism (Eagles 2014) in view of the increasing incidence of "overtourism" in national parks (Menzione 2018; Kruczek and PrzybyłoKisielewska 2018).

Such studies are performed for the purpose of visitor volume modelling (Cole and Daniel 2003) as well as the determination of the intensity of park use (Wolf et al. 2012) and the determination of the motivations and preferences of tourists in national parks. Visitor surveys also remain an essential tool in park visitor research (Wolf et al. 2012).

The details of trip itineraries needed to examine variation in tourism intensity at sites, especially if they vary on a fine spatial scale, may likely not be adequately captured. Nevertheless, surveys may provide additional, useful information for explaining travel patterns when they are combined with other monitoring methods (Wolf et al. 2012). Due to the mountainous nature of the study area, the review and discussion herein are limited to the publication of data from other mountain areas of Europe. Numerous monitoring techniques are described in previous research studies and can be grouped after Cessford and Muhar (2003) into four types: i) direct observations - using staff observers or camera recording; ii) on-site counters - devices recording and storing visitor counts; iii) visits registrations counting permits issued or records in registers; iv) inferred counts - other data used to provide on-site estimates. Based on literature review further methods for visitors monitoring can be distinguished: direct observations by observers (Hartmann1988; Keul and Kühberger 1997; Murphy 1992; Hibner et al. 2018), self-managed travel diaries (Fennell 1996; Thornton et al. 1997), self-counting techniques such as voluntary visitor registration (Watson et al. 2000), spatial patterns of itinerary mapping (Connell and Page 2008), using of on-site pyroelectric sensor (devices recording and storing on-site visitor count data)
(Hornback and Eagles 1998; Watson et al. 2000) and proxy measures (e.g., camping permits) from which visitor numbers may be estimated (Cessford and Muhar 2003), vehicle counting, automated pyroelectric sensor, and ranger observations (McIntyre 1999), using of statistical measures (regression analysis) (Hlavackova et al. 2018). Nowadays the use of electronic devices has become increasingly popular in visitor monitoring. Specifically in mountain areas, infrared traffic pyroelectric sensors have become prevalent, together with digital imaging and transmission technology (Kammler and Schernewski 2004 Guillen et al. 2008, Svajda 2009; Fairfax et al 2012). Greater use of other methods has also been observed including global positioning systems (GPS) (Shoval and Isaacson 2010, Taczanowska et al. 2014; Bielański et al. 2018, Rota et al. 2019); motion-sensing cameras (henceforth referred to as "camera traps"). The latter are used to gather data on tourists passing a given point along a trail (Campbell 2006; Miller et al. 2017) and on illegal tourism (Sitarz et al. 2018). Other tracking devices such as tourist timing systems (i.e., ankle-mounted transmitters monitored by receivers located in a network) (O'Connor et al. 2005) have also been employed. Arnberger et al. (2005) presented a comparison of visitor-monitoring methods evaluating their costs and data quality in order to recommend the best available methods. For automated methods, counter calibration is an important issue (Ross 2005; Oddgeir et al. 2013; Miller et al. 2017). Additionally, selected authors have presented a verification algorithm for visitor's data (Farinas and Morera 2018; Hlavackova et al. 2018; Rogowski 2018b).

\section{Material and Methods}

\subsection{Study area}

Stołowe Mountains National Park (SMNP) is located in the Sudety Mountains in south-western Poland, along the border with the Czech Republic (Figure 1). The area is situated in the Variscan orogenic belt of Europe. The unique physical appearance of the Stołowe Mts. stands in stark contrast to many other mountains massifs in the Sudety Mts. due to the presence of nearly flat-lying, Cretaceous sandstone beds at relatively high 
elevations. Therefore, the overall morphology of the area is of stepped tableland type, climbing from ca. $400 \mathrm{~m}$ a.s.l. to $919 \mathrm{~m}$ a.s.l. at the highest summit, which gives the mountain range a tiered geomorphological structure. "Normal" mountain relief, with closely spaced deep valleys and narrow watersheds also occurs in the Stołowe Mts. but is not associated with their sandstone bedrock (Migoń 2012).

The total area of SMNP is 6340 ha with ca. 100 $\mathrm{km}$ of hiking trails, $70 \mathrm{~km}$ of bike trails and $20 \mathrm{~km}$ of cross-country skiing trails and a few climbing routes. The SMNP was selected as the study area because of three following reasons:

1. Until recently, there was a lack of an accurate visitor's data in the SMNP. Even though, the park is claimed as one of the most popular national park in Poland. The official statistics on the number of visitors were 286 thousand in 2016 (Environment, 2017), were highly inaccurate, and were assessed based only on the entrance fees counts. Entrance fees in SMNP are issued only in two the most popular attractions - Szczeliniec Wielki and Błędne Skały. As shown by the MSTT - see Results section - entrance fees counts represent approximately $60 \%$ of total number of visitors;

2. Park managers reported an increasing problem with the mass tourism. Park managers need an accurate visitor's data in order to efficiently manage the tourist traffic in the park and to update the strategic documents;

3. The relatively small area of the park together with high-developed trail network and easily accessible trailheads make this park suitable for a comprehensive visitors monitoring and testing pyroelectric sensors.

\subsection{Monitoring System of tourist traffic (MSTT)}

The Monitoring System of tourist traffic (MSTT) in SMNP was established in 2016. The aim of the MSTT was to accurately quantify tourist traffic. Moreover the project aimed to evaluate the usefulness of the automated measuring system of visitor flow in a mountain area. The MSTT had the following measurement techniques:

- pyroelectric sensors mounted on each trailhead,

- questionnaire-type surveys to assess park visitors' motivations, preferences and behaviour.

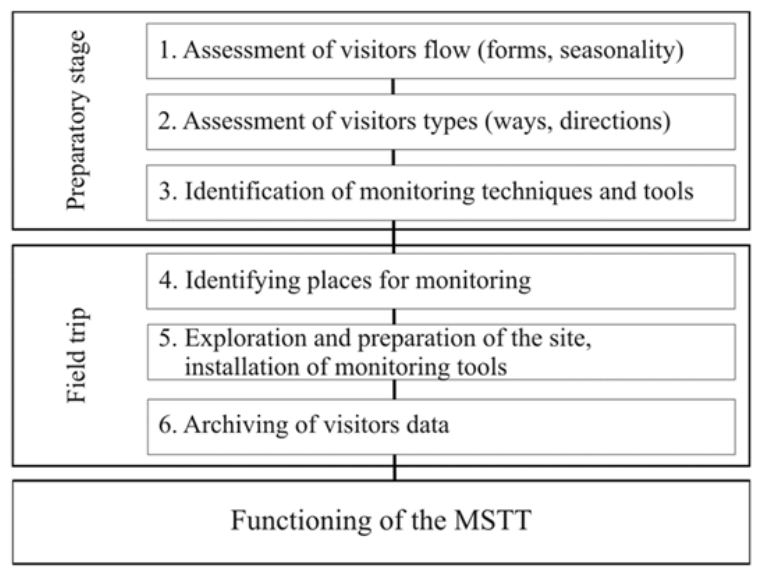

Figure 2 Scheme of the Monitoring System of tourist traffic (MSTT) in Stołowe Mountains National Park.

The creation of the system was preceded by a number of fieldwork tasks (Figure 2).

The preparatory stage included three tasks: assessment of visitor flow, visitor type and determination of monitoring method.

\subsubsection{Assessment of visitor flow (forms, seasonality)}

The first stage of research involved an assessment of forms of visitor flow in accordance with existing legislation in Poland. Then, the share of each type of flow in the overall tourist traffic structure was assessed based on available data. This step helped to assess the main forms of visitor flow to be covered by monitoring along with seasonality effects. In the study area, visitor flow takes the form of hiking, cycling, cross country skiing, climbing and driving. Hiking prevails within the studied national park and it is allowed throughout the year, with the exception of tourist trails in the area of Błędne Skały and Szczeliniec Wielki, which are closed in the winter. The car traffic is allowed all the time, but there is also a public road running through the park which serves the transportation needs of the local community. Cycling, cross country skiing and climbing are of secondary importance and are highly seasonal. In view of the above, it was decided to hiking monitor throughout the year. Other forms of tourism will be subject to monitoring in subsequent years.

\subsubsection{Recognition of visitor flow types (ways, directions)}

In the second stage of the MSTT the analysis included the assessment of a network of hiking trails and educational trails, and verification of 
rules for tourist traffic in the park. In accordance with these, tourist traffic is only allowed on marked hiking, cycling, cross country skiing trails, educational trails and public roads. In the park there are: 11 hiking trails, 5 educational trails, 5 cycling trails, 3 cross-country ski trails, 5 public roads and 6 climbing areas. There are short sections where specific types of tourist trails come together, as a result of which the given trail is used by different types of tourists, e.g. hiking and cyclists. Moreover, certain sections of trails are marked one-way, and there is one section of road with one-way and alternating-direction car traffic.

\subsubsection{Identification of monitoring techniques and tools}

In the third stage, the final selection of monitoring techniques and tools was carried out. Identification of monitoring techniques and tools included both natural and infrastructural conditions of the national park: uniqueness of landscape features, network of tourist trails, location of the national park boundary, data precision, data processing capacity and tools maintenance. Previous visitors monitoring techniques (based on entrance fees counts) were not accurate. Therefore two monitoring techniques were chosen: i) infrared pyroelectric sensor (EcoCounter sensors that allowed the measurements of visitors flow in both directions were utilized); ii) Pen-and-Paper Personal Interview (PAPI) surveys conducted in order to find out the visitor's motivations, preferences and behaviour. The selection of these monitoring techniques was based on pilot studies conducted. One pyroelectric sensor has been tested for two years preceding the MSTT and provided first quantitative assessment of visitors flow. As well PAPI surveys were performed in 2015. According to park managers the results of both pilot studies were satisfactory.

\subsubsection{Identifying places for monitoring}

In order to obtain valuable results corresponding to reality, it was crucial to analyse the studied network of hiking trails along with the location of the national park boundary to identify places to install counting devices. It was decided to install infrared traffic pyroelectric sensor on every hiking trailhead at the national park boundary and on parking areas located by the public road running through the national park.

A total of 38 sites for the installation of pyroelectric sensors were identified: 22 at the national park boundary, 11 close to parking spots by the public road. An additional 5 locations for pyroelectric sensors were identified inside the park at sites with the most intense tourist traffic: 3 near Szczeliniec Wielki and 2 near Błędne Skały. All the devices were installed in 2016. One pyroelectric sensor had already been installed earlier on a trail inside the rocky-labyrinth of Błędne Skały. The scope of the data generated included hourly, daily, weekly, monthly, and annual reports, taking into account the direction of traffic measuring both directions: entries (IN), exits (OUT) and passages (IN+OUT).

As a result, data were collected using 39 pyroelectric sensors (Figure 1). There were five types of pyroelectric sensor locations:

1. on the national park border (22 pyroelectric sensor); counting visitor entrances (IN) and exits (OUT) into/from the national park ;

2. on tourist trails marked on public roads (11 pyroelectric sensor), counting visitor entrances (IN) and exits (OUT) from tourist trails from public roads inside the national park;

3. located at the most popular attractions (i.e., Szczeliniec Wielki, Błędne Skały) (6 pyroelectric sensor), counting visitors on one-way trails.

Approximately 936 hourly automated measurements were recorded every day in the course of the study. Data was downloaded from counting devices via Bluetooth technology through an application on a mobile device. Due to weak cell-phone reception in the study area the remote data download was not available. The data were analysed using a statistics spreadsheet.

The PAPI surveys were made in the area of the most popular attractions, i.e., Szczeliniec Wielki and Błędne Skały. These are the most attractive places in the park which would allow to assess the opinion of a large group of respondents. Tourist traffic in these areas includes both visitors who are inexperienced and experienced in nature conservation issues and those who do not know the specificities of the area as well as those who are experienced and informed about the park. The surveys were performed in 16 randomly chosen days, i.e. 8 weekdays and 8 weekends during each tourist season (i.e. in mid-spring, mid-summer, 
mid-autumn and mid-winter). In each survey day, four interviewers were performed survey questionnaires from 9 a.m. to 5 p.m. In total there were c.a. 2500 survey questionnaires performed in period from 2016 to 2019. For the purpose of this paper 468 questionnaires from 2017 have been summarized.

The survey questionnaire consisted of questions designed to determine visitor sociodemographic structure as well as visitors' motivations, preferences and behaviour. Survey questions concerned issues such as ways of reaching the national park and its attractions, purpose of tourist visits and their duration, frequency of visits, names of the visited places, types and locations of tourist accommodation and catering facilities, and requested an assessment of the tourist offering in the region (Rogowski and Małek 2016).

\subsubsection{Exploration and preparation of the site, installation of monitoring tools}

As part of fieldwork, it was necessary to visit pre-selected sites in order to approve them and prepare each site for the installation of pyroelectric sensors. The installation of pyroelectric sensors involved their placement inside wooden poles or somewhere in natural field conditions (e.g., in rock cracks or tree trunks). Each sensor was mounted at $0.7 \mathrm{~m}$ height off the ground. Measurement points were selected taking into consideration the width of the trail and the maximum pyroelectric sensor detection range, which is up to 2 meters. The pyroelectric sensors were installed in places hidden from tourists' sight, which allowed the devices to count visitor passes in both directions. Right after installation, each device was checked for its ability to accurately transfer data.

\subsubsection{Archiving of visitors data}

The visitors data reading and transfer process required at each site an activation of the counting device and data transfer via Bluetooth to an application downloaded onto a mobile device. As data are registered in the pyroelectric sensor memory, it is possible to prepare a visitor flow report at various resolutions (i.e., hourly, daily, weekly and monthly) and distinguish between IN and OUT tourist passages. Data readings from each pyroelectric sensor were performed on a bimonthly basis. In this paper only the sample data from year 2017 are presented. This was done in order to highlight the utility of the MSTT and not to discuss the results of visitors monitoring itself. Details description of results was presented in previous works (Rogowski 2017a, b; Rogowski 2018a).

\subsubsection{Functioning of the MSTT}

Visitors data were summarized and presented in tabular form, whereas selected results were illustrated on a map. The frequency of entries was determined based on the location of pyroelectric sensor for different seasons and regions in order to determine fluctuations and the intensity of visitors flow in the park. For attractions near which no pyroelectric sensors were located, an algorithm was developed to calculate visitor traffic volume. In order to estimate the total number of visitors in SMNP the number of entries (IN) from 33 pyroelectric sensors located at the trailheads were summarized. Whereas, in order to estimate the total number of visitors in two the most popular tourist attractions - Szczeliniec Wielki and Błędne Skaty - the number of entries (IN) from each pyroelectric sensor mounted at these attractions were considered.

Pyroelectric sensors data were subjected to onsite calibration. The on-site calibrations were performed during three daily campaigns executed in high, mid- and low season, i.e., mid-August, mid-October and mid-January respectively. This procedure consisted of manual counting of each visitor passing by two selected pyroelectric sensors. The measurements were performed from 8:00 AM to 6:00 PM on one heavily loaded (Szczeliniec Wielki) and one less loaded trail. In total, in three days there were 449 counts of visitor passes recorded on two measuring points. The results with errors range from the entire studied year were analysed in a report submitted to the national park's management and were also made publicly available.

\section{Results}

The data obtained from the MSTT allowed to produce a detailed description of tourist traffic in the studied national park as a whole (Table 1). The data collected by the MSTT enabled multidimensional analysis of visitors. 
The first completed data of visitors flow were acquired for entire 2017 and 2018 year, and were previously presented in separate study (Rogowski 2017a,b; Rogowski 2018a). The results presented in this section aim to highlight the potential of the MSTT and not to characterize the visitor flow in the SMNP per se.

The visitors flow is distinguished by its strong spatial and seasonal concentration. In 2017 a total of 871,344 visitors were recorded to have visited the park. The SMNP is the second most popular tourist destination in the Sudety Mountains. It is one of the most popular national parks in Poland, as evidenced by the MSTT data. Almost 2/3 of the total visitors $(511,303)$ were recorded in summer (i.e. form June 1 to August 31). July and August $(380,350)$ generated $44 \%$ of the total annual number of visitors. The number of visitors recorded in spring, i.e. from March 1 to May 31
(211,077) was little more than the number of visitors recorded in July $(190,517)$. Considering spring season, the highest number of visitors was recorded in May $(162,840)$. This was due to high frequency of school groups visits. From May 1 to August 31 there were 674,143 visitors recorded, which encompassed $77 \%$ of the total annual number of visitors in the SMNP. This period constitutes the high tourist season. In autumn (i.e. from September 1 to November 30) and in winter (i.e. from December 1, 2017 to February 28, 2018) there were 111,828 (13\%) and 26,348 (3\%) visitors noted in the SMNP respectively. The months of September, October and April generated mean monthly number of visitors from 35,000 to 60,000 . These months represent the mid-season. The low season was represented by the period from November 1, 2017 till February 28, 2018 (Figure 3). Visitors flow seasonality obtain from pyroelectric

Table 1 Typology of visitors data collected by the Monitoring System of tourist traffic (MSTT) in Stołowe Mountains National Park

The data via pyroelectric sensors

Number of visitor entries (IN) and exits (OUT) on tourist trails aggregated into annual, monthly, weekly, daily and hourly reports for the studied national park and for selected attractions

Level of tourist attraction popularity aggregated for annual, monthly, weekly, daily and hourly periods

Estimated time periods and sites with the largest and smallest numbers of visitors

Tourist trail volumes
The data via survey questionnaires

Socio-demographics of tourists (sex, age, origin)

Motivation for tourist activity

Characteristics of tourist stay (ways of reaching the national park, purpose of visit, visit duration, frequency of visits, visited attractions, use of lodging and catering facilities and their location)

Evaluation of the local tourist offering

Assessment of strengths and weaknesses of tourism in region

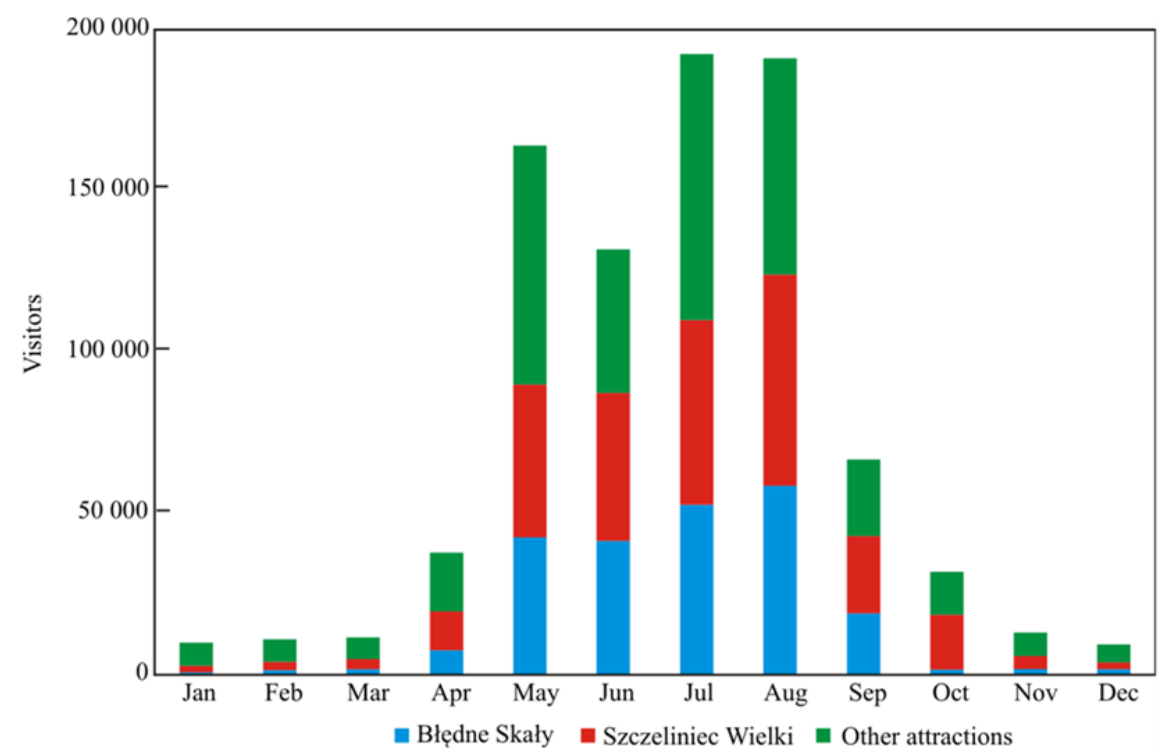

Figure 3 Total monthly distributions of visitors counts (entries only) in the Stołowe Mountains National Park in 2017. Visitor counts at two of the most popular attractions included Błędne Skały (black bars) and Szczeliniec Wielki (dark grey bars). Light grey bars represent all other monitored spots. 
sensors was confirmed by the PAPI surveys, where $60 \%$ of the respondents decelerated (in multiple choice questions) summer visits, $33 \%$ spring visits, $28 \%$ autumn visits and $17 \%$ winter visits.

Holiday periods generated from $19 \%$ to $64 \%$ of the monthly number of visitors. These periods were associated with Christmas, New Year's, Easter, as well as holiday weekends in May (Labour Day), June (Corpus Christi), August (Assumption of the Virgin Mary) and November (Impendence Day). During these holiday periods, daily visitor counts were always the highest. In addition, the high season of school group visits was shown to be from the $16^{\text {th }}$ to the $25^{\text {th }}$ of May 2017 with almost 65,600 visitors, which accounted for nearly half of the monthly number of visitors (Rogowski 2018a).

The daily number of visitors in the SMNP in 2017 varied substantially. On average, there were 2,300 visitors per day. Maximum daily visitors exceeded 10,000 and were recorded during the following holiday periods (Table 2).

Daily visitor counts confirmed the division into a low, mid and high season. Medians for high seasons daily were from 4,000 to 6,000 visitors. The highest medians were noted for July and August. Maximum daily visitors in the high season were associated with holiday periods (Figure 4). Minimum visitors were higher than the maximum daily visitors recorded in the low season. Visitor counts for September and October were represented by a broader distribution and higher maximum values, however, with lower medians. The daily visitor count distribution in April was the broadest, which indicates the onset of the high tourist season, as shown by some of the highest daily maximum numbers of visitors recorded on April $30^{\text {th }}$. Medians for daily visitors in April were low. In three months, assigned mid-season, an increased number of visitors was noted specifically during weekends. Low medians and a narrow distribution of daily visitor counts indicated a low tourist season in January, February, March, November, and December (Figure 4).

Szczeliniec Wielki was a most popular attraction (Figure 5). In 2017 were recorded a total of 283,214 visitors. In Błędne Skały were recorded in while 231,209 visitors. This is confirmed by the statements of PAPI survey respondents who state that they visit these two tourist attractions most frequently: Szczeliniec Wielki (73\% of respondents) and Błędne Skały (57\%). More than half visitors were recorded in summer in Szczeliniec Wielki $(168,656)$ and in Błędne Skały (152 830). August was the month when both attractions were visited most frequently: 65,464 visitors in Szczeliniec Wielki and 58,617 in Błędne Skały. Other attractions were less often visited, i.e. Skalne Grzyby (31,719 visitors), Narożnik (20,080), Radkowskie Skały $(16,755)$ and Karol's Fort $(8,602)$. These attractions were also mentioned in the PAPI surveys, i.e. Skalne Grzyby (7\%), Narożnik (6\%), Radkowskie Skały (3\%), Karol's Fort (2\%).

The results of the PAPI surveys have shown that $66 \%$ of respondents have visited the SMNP for 
leisure-related purposes, $20 \%$ to nature-based tourism and $10 \%$ to pursue active tourism. The differences in responses depending on the season of the year were found to be minor. The greatest difference was reported for active tourism. Due to the low popularity of winter activities (in this case, cross-country skiing), this purpose of tourism was the least often reported by tourists in the park (1\%). During other seasons of the year, $8 \%$ to $13 \%$ of survey respondents reported pursuing active tourism. Tourists' motivations for visiting have an important impact on the choice of destination. Tourists visiting SMNP usually arrive there by car (81\%), which is facilitated by convenient and successively improved road infrastructure. A car is particularly popular among those travelling with their families (91\%), while other tourists travel by public transport: by train or bus (about 10\%). In comparison with a previous study, the number of visitors in the park increases every year; the latest data indicate that visitors flow in 2018 increased about $20 \%$. These are mostly young people (up to 26 years old -12\%). For moving around the park area, the car remains the most frequently used means of transport given the under-development of public transport in the region. In 2017 the car was selected by $45 \%$ of survey respondents, but its share in subsequent years decreased in favour of increasingly common pedestrian access to main attractions; walking was the main mode of transport of $50 \%$ of survey respondents.

Initial research results revealed relationships between motivation, duration of visits and their place of residence. Leisure tourism was the primary motivation to visit the park for all the survey respondents. Tourists arrived to the SMNP from distant regions and stayed an average of 4 to 7 days. A secondary motivation to visit the SMNP was to nature-based tourism and active tourism. Tourists visited the SMNP most frequently in summer (68\%) and spring (37\%). This result was confirmed via qualitative monitoring by means of pyroelectric- electric sensor.

The pyroelectric sensors were not free from the measuring errors. According to auto-calibration works performed, conducted however in the Karkonosze National Park (Rogowski 2018b), the mean sensor error rate can be estimated at $10 \%$. In the frame of the MSTT on-site calibration of pyroelectric sensors was performed. The results of on-site calibration conducted in the SMNP have revealed similar error rate. The highest differences between manual and automated pyroelectric counts have occurred in the periods characterized by the highest visitors flow. Erroneous counts were observed during groups passing when intervals between single visitors passing were shorter than 2 seconds. Among the 428 visitor's passes recorded during on-site calibration $44 \%$ have releveled errors. The maximum error, considering both overand underestimations, has reached from $15 \%$ to $18 \%$. The mean error rate was at a level of $10 \%$. The visitors counts errors were not recorded for visitor's passes that occurred at the intervals longer 
that 2 second as well for the groups smaller than six persons. The detailed description of on-site calibration results will be presented in separate study. The result of on-site calibration will help to verify error rate of visitors counts in the MSTT.

\section{Discussion}

The MSTT has provided comprehensive results on visitors flow in the SMNP. The advantage of the system is that it operates throughout the entire calendar year. Six stages of the creation of the MSTT were taken into account in the study. The most optimal methods, among those presented by previous authors (Cessford and Muhar 2003; Kajala 2007), were selected and applied in the MSTT. The combination of two main measuring techniques, i.e. monitoring by use of pyroelectric sensors and PAPI surveys, enabled a robust description of visitors flow in the SMNP. The author believe that presented methodology can be applied to other mid-mountain areas as a useful tool in the tourism management of the national park.

By juxtaposing individual entrances, one can determine the popularity of park attractions or indicate the spatial distribution of visitors in a national park and changes therein over time. The number of visitors according to MSTT application can be calculated based on monthly, daily, and hourly entries. This allows to produce a visitor entry model for park attractions of high, medium, and low popularity. Moreover, it is also possible to indicate the susceptibility of tourist traffic to seasonality with respect to particular attractions, distinguishing attractions with a high, medium and low degree of susceptibility to seasonality. Interpolating numerical data for trail sections one can determine the intensity of visitors flow, indicating sections with high, medium and low intensity of visitors flow.

The SMNP is a suitable destination for short breaks leisure visits in wilderness. Almost 2/3 of the total visitors $(511,303)$ were recorded in summer. From $19 \%$ to $64 \%$ of the monthly number of visitors were recorded during holiday periods. The duration of high tourist season was established by monthly and daily visitor's counts and assigned to the period from May 1 to August 31. During these periods the study area is subjected to masstourism. This was confirmed in PAPI surveys. Indeed, the problem of masstourism in the SMNP is increasing. In 2018 a total increase of $22 \%$ in visitors flow was noted in the park, whereas at Szczeliniec Wieki the increase of $32 \%$ was reported. The problem of overtourism in national parks is increasingly reported (Mezione 2018; Peeters et al. 2018; Kruczek and Przybyło-Kisielewska 2018; Simmonds et al. 2018; Milano et al. 2019).

Additionally the outcomes the MSTT were incorporated into Tourist Carrying Capacity (TCC) estimation. The TCC estimation was computed for two hiking trails including Szczeliniec Wielki and Błędne Skały (Rogowski 2019). The TCC estimations incorporated trail width measurements, plant habitats neighbouring the trail and tourists satisfaction (Figure 5). Finally, the optimal distance between the visitors on a trail was determined. The TCC estimations were compared with visitor number in hourly resolution obtain from MSTT i.e. pyroelectric sensors data. As a result periods exceeding TCC were distinguished together with interim limits in the park (Rogowski 2019). Propose limits will be tested in 2020.

\section{Conclusion and Perspectives}

The data collected by the MSTT enabled multilevel and robust characterization of tourist traffic in the SMNP. The MSTT data are continuously transferred to the national park managers allowing for adequate reaction in order to effectively manage tourism in the park area. Application of homogeneous measurement techniques across three years, enabled a data comparison between years and determination of tourist traffic trends.

The current functioning of the studied system requires a continuous monitoring of the condition of pyroelectric sensors and continuous reading of data.

The presented methodology of the MSTT could be applied to other mid-mountain national park areas. In order to sustain the MSTT methodology in the long-run the following guidelines and workload estimates should be taken into account:

- before selecting the monitoring techniques, landscape type and organization of tourist traffic in 
the study area need to be analyzed. Both factors determine to the greatest extent the monitoring techniques and tools that will make the system more effective in providing reliable data;

- Visitors data acquisition from pyroelectric should be performed once per month, not less frequent;

- During each data acquisition campaign the sensors should be maintained, this mainly includes detectors cleaning and verification of potential wildlife and human impacts;

- Considering 39 pyroelectric sensor used in this study, the visitors data acquisition and maintenance of pyroelectric sensors required ca. 36 mandays, i.e., 288 hours of field work annually;

- Additionally, time required for troubleshooting activities has to be taken into account (i.e., sensor replacement and mitigation of unexpected wildlife and human impacts). In this study this consumed in average 10 mandays, i.e., 80 hours annually;

- Visitors data calibration is highly recommended. On-site calibration campaigns should be performed in a first measuring year at least three times, i.e., once per high, mid- and low season. The calibration should encompasses at minimum two pyroelectric sensors, for e.g. those mounted at heavily loaded and less loaded trail. In this study the on-site calibration was performed on two trails and consumed 6 mandays, i.e., 48 hours;

- All estimates of required workload in relation to system maintenance have to consider the average access time between the pyroelectric sensors. In this study this time was very short and equaled 30 minutes;

- it is recommended that well-trained and the same person is delegated to system maintenance in a long-term;

- Visitors data processing require statistical tools. Data analyses should be performed in close collaboration between research sector or academia and park managers.

Major limitation of the MSTT could consider financial aspect of the system, specifically the costs of high replication of pyroelectric sensors. Additionally, for some park managers required mandays for MSTT maintenances and data acquisition might be consider as limitation. Both limitations could be potentially overcome by longterm planning of the MSTT application in a given area, including external grants contribution.

In total 39 pyroelectric sensors were used in this study. High replication of measuring devices allowed for continuous visitors monitoring performed on each trailhead. To my knowledge this might be the first application of such high number of pyroelectric sensors being used in a single study area. Giving a large number of devices used, the results of the MSTT could be useful in the follow up-studies, such as:

- Spatio-temporal characteristic of visitor flow in various temporal resolutions, such as annual, seasonal, monthly, daily and hourly;

- Identification of visitor types in national park including socio-demographic characteristics, visitors motivation and behaviour. The visitors trends can by analysed among years. As a product, list of recommendations for local tour operators and policymakers can be provided in order to create a more sustainable tourist offer for the Stołowe Mts. cross-border region;

- Modelling and forecasting visitors flow using correlation matrix between daily pyroelectric sensors data. Both studies can be helpful in detecting incorrect data and/or imputing the missing values;

- Estimation of economic impact of tourism in a given region and role of visitors types in local economy for example: accommodation and gastronomy sectors, local air-crafts businesses,

- Calculation of Tourism Carrying Capacity (TCC) of trails network in the national park in order to monitor the masstourism and potential of overtourism.

Further work on the development of the MSTT should be connected with the monitoring of other forms of tourist activity in the national park, i.e. climbing, cycling, cross country skiing. This will provide a holistic characteristic of tourist traffic in the study area. In addition, the MSTT should also aim to monitor illegal tourism, determined its magnitude, structure and spatial patterns. This is especially the case of unmarked paths, where trespassing remains a recurring problem. Considering a multilevel aspect of the MSTT, the system provides powerful tools for tourism management in national parks. 


\section{Acknowledgements}

This research has been conducted in cooperation with Stołowe Mountain National Park, supported by Forest Found (DU/30/2018), Lasy Państwowe (Poland).

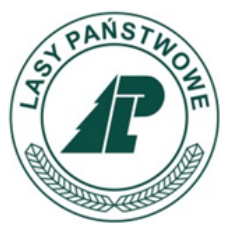

\section{Open Access}

This article is distributed under the terms of the Creative Commons Attribution 4.0 International License (http://creativecommons. org/licenses/by/4.o/), which permits unrestricted use, distribution, and reproduction in any medium, provided you give appropriate credit to the original author(s) and the source, provide a link to the Creative Commons license, and indicate if changes were made.

\section{References}

Arnberger A, Haider W and Brandenburg C (2005) Evaluating visitor-monitoring techniques: a comparison of counting and video observation data. Environmental Management 36: 317327. https://doi.org/10.1007/s00267-004-8201-6

Bielański M, Taczanowska K, Muhar A, et al. (2018) Application of GPS tracking for monitoring spatially unconstrained outdoor recreational activities in protected areas - A case study of ski touring in the Tatra National Park, Poland. Applied Geography 96: 51-65.

https://doi.org/10.1016/j.apgeog.2018.05.008

Beunen R, Regnerus HD, Jaarsma CF (2008) Gateways as a means of visitor management in national parks and protected areas, Tourism Management 29: 138-145.

https://doi.org/10.1016/j.tourman.2007.03.017

Campbell M J (2006) Monitoring trail use with digital still cameras: Strengths, limitations and proposed resolutions. In: Siegrist D, Clivaz C, Hunziker M, and Iten S (Eds.), Exploring the Nature of Management Proceedings of the Third International Conference on Monitoring and Management of Visitor Flows in Recreational and Protected Areas Switzerland: Rapperswill. pp 317-321

http://mmv.boku.ac.at/refbase/files/campbell_michael_j.2006-monitoring_trail_use.pdf

Cessford, G and Muhar A (2003) Monitoring options for visitor numbers in national parks and natural areas. Journal for Nature Conservation 11: 240-250. https://doi.org/10.1078/1617-1381-00055

Chhetri P, Arrowsmith C, Jackson M (2004) Determining hiking experiences in nature-based tourist destinations. Tourism Management 25: 31-43.

https://doi.org/10.1016/So261-5177(03)ooo57-8

Cole DN, Daniel TC (2003) The science of visitor management in parks and protected areas: from verbal reports to simulation models. Journal for Nature Conservation 11: 269277. https://doi.org/10.1078/1617-1381-00058

Connell J, and Page SJ (2008) Exploring the spatial patterns of car-based tourist travel in Loch Lomond and Trossachs National Park. Scotland Tourism Management 29: 561-580. https://doi.org/10.1016/j.tourman.2007.03.019

De Lucio JV, Mubica M (1994) Landscape preferences and behavior of visitors to Spanish national parks. Landscape and Urban Planning 29: 145-160.

https://doi.org/10.1016/0169-2046(94)90024-8

Eagles, PFJ (2014) Research priorities in park tourism. Journal of Sustainable Tourism 22: 528-549.

https://doi.org/10.1080/09669582.2013.785554

Envionment, Statistical Information and Elaboration, Central Statistical Office, Warszaw (2017)

https://stat.gov.pl/files/gfx/portalinformacyjny/pl/defaultak tualnosci/5484/1/18/1/ochrona_srodowiska_2017.pdf

Farías EI, Grau HR, Camps A (2005) Trails preferences and visitors' behavoir to Aigüestortes i Estany de Sant Maurici
National Park. Spain. Journal of Mountain Research and Development 25: 51-59. https://doi.org/10.2307/3674369

Farias-Torbidoni EI (2011) Managing for Recreational Experience Opportunities: The Case of Hikers in Protected Areas in Catalonia, Spain. Environmental Management 47: 482-496. https://doi.org/10.1007/so0267-010-9606-z

Farias-Torbidoni EI, Morera S (2018) Optimizing the use of the Eco-counters tool A case of study. The 9th International Conference on Monitoring and Management of Visitors in Recreational and Protected Areas (MMV9), Bordeaux, France https://mmv9.sciencesconf.org/data/pages/last_version_abs tract_book_7.pdf

Fairfax RJ, Dowling RM, and Neldner VJ (2012) The use of infrared sensors and digital cameras for documenting visitor use patterns: A case study from D'Aguilar National Park, south-east Queensland, Australia. Current Issues in Tourism 17(1): 72-83. https://doi.org/10.1080/13683500.2012.714749

Fennell D (1996) A tourist space-time budget in the Shetland Islands. Annals of Tourism Research 23: 811-829. https://doi.org/10.1016/0160-7383(96)oooo8-4

Guillen J, Garcia-Olivares A, Ojeda E, et al. (2008) Long-term quantification of beach users using video monitoring. Journal of Coastal Research 24: 1612-1619. https://doi.org/10.2112/07-0886.1

Hartmann R (1988) Combining field methods in tourism research. Annals of Tourism Research 15: 88-105. https://doi.org/10.1016/0160-7383(88)90073-4

Hibner J, Taczanowska K, Zięba A, et al. (2018) Visitor profiling for cable car mountain destinations as a basis for protected area management: a case study of the summer season in the Tatra Mountains at Kasprowy Wierch (Poland) and Skalnaté Pleso (Slovakia), ecomont. Journal on Protected Mountain Areas Research and Management 10: $24-35$. https://doi.org/10.1553/eco.mont-10-1s24

Hlavackova P, Slovackova H, Brezna D, Michal J (2018) Comparison of results of visitor arrival monitoring using regression analysis. Journal of Forest Science 64(7): 303- 312. https://doi.org/10.17221/20/2018-JFS

Hornback KE, and Eagles PFJ (1998) Guidelines for public use measurement and reporting at parks and protected areas Gland, Switzerland. World Commission on Protected Areas, World Conservation Union (IUCN)

https://portals.iucn.org/library/sites/library/files/document s/1999-018.pdf

Kajala L, Almik A, Dahl R, et al. (2007) Visitor monitoring in nature areas - a manual based on experiences from the Nordic and Baltic countries. Swedish Environmental Protection Agency, Stockholm, Sweden. p 205

https://www.naturvardsverket.se/Documents/publikationer/ 620-1258-4.pdf

Kammler M and Schernewski G (2004) Spatial and temporal analysis of beach tourism using webcam and aerial 
photographs. Managing the Baltic Sea Coastline Reports 2: 121-128. https://baltcoastinline.databases.eucc-d.de/files/ documents/ooooo381_Kammler_Schernewski.pdf

Keul A, Kühberger A (1997) Tracking the Salzburg tourist. Annals of Tourism Research 24: 1008-1012. https://doi.org/10.1016/So160-7383(97)00038-8

Konu H, Kajala L (2012) Segmenting Protected Area Visitors Based on Their Motivations. Report number: Nature Protection Publications of Metsähallitus 194, Savonlinna. https://julkaisut.metsa.fi/assets/pdf/lp/Asarja/a194.pdf

Kruczek Z and Przybyło-Kisielewska K (2018) Tourist traffic of national parks and consequences of excessive frequency visitors, In book, National Parks and socio-economic environment, Condemned to dialogue, The University College of Tourism and Ecology in Sucha Beskidzka, Poland (In Polish)

McIntyre N (1999) Towards Best Practise in Visitor use Monitoring Processes: A Case Study of Australian Protected Areas. Parks and Leisure 24-29.

https://www.cabdirect.org/cabdirect/abstract/19991810658

Menzione A (2018) US National Parks Face Overtourism. https://wwwglobaltravelerusacom/u-s-national-parks-faceovertourism/, accessed on 2019-09-15.

Migoń P (2012) Geographical setting and general landscape, Kasprzak M, Migoń P Góry Stołowe, Geology, Landforms, Vegetation, Patterns and Human Impact, University of Wrocław, Wrocław. http://www.geogr.uni.wroc.pl/data/files/ publikacje-pozostale-publikacje-igrr/lib-gory_stolowe.pdf

Milano C, Cheer JM, Novelli M (2019) Overtourism, Excesses, Discontents and Measures in Travel and Tourism. Ostelea School of Tourism and Hospitality - University of Lleida, Spain, Joseph M Cheer, Wakayama University, Japan, Marina Novelli, University of Brighton, UK.

https://doi.org/10.1080/13032917.2019.1690794

Miller A, Yu-Fai L, Kays R (2017) Coupling visitor and wildlife monitoring in protected areas using camera traps. Journal of Outdoor Recreation and Tourism 17: 44-53.

https://doi.org/10.1016/j.jort.2016.09.007

Murphy P (1992) Urban tourism and visitor behavior. American Behavioral Scientist 36: 200-211.

https://doi.org/10.1177/0002764292036002007

O'Connor A, Zerger A, and Itami B (2005) Geo-temporal tracking and analysis of tourist movement. Mathematics and Computers in Simulation 69: 135-150.

https://doi.org/10.1016/j.matcom.2005.02.036

Oddgeir A, Vegard G, Wold LC, Stange E (2013) Monitoring visitors to natural areas in wintertime: issues in counter. Journal of Sustainable Tourism 22(4): 550-560. https://doi.org/10.1080/09669582.2013.839693

Peeters P, Gössling S, Klijs J, et al. (2018) Research for TRAN Committee - Overtourism: impact and possible policy responses. European Parliament, Policy Department for Structural and Cohesion Policies, Brussels. https://doi.org/10.2861/919195

Geoffrey KR, Peterson BA, Beeco JA and Brown G (2018) Understanding visitors' spatial behavior: a review of spatial applications in parks. Tourism Geographies 20(5): 833-857. https://doi.org/10.1080/14616688.2018.1519720

Rogowski M, Małek B (2016) The Visitors monitoring in the Stołowe Mts. National Park - the objective of project and preliminary results, Tourist development: determinants and plans. Volume XVIII - Nature tourism and conditions of its development, Bogucki Scientific Publisher, Poznań, Poland. (In Polish) http://turystyka.amu.edu.pl/tomy/tir16.pdf

Rogowski M (2017a) Mountain hiking in the Stołowe Mountains National Park. Turyzm/Tourism 27(2) : 89-97.; https://doi.org/10.1515/tour-2017-0017

Rogowski M (2017b) Monitoring System of tourism traffic (MSTT) in the Stołowe Mts. National Park - principles a preliminary results (in polish). Studia i Materiały CEPL w Rogowie 158-165
http://cepl.sggw.pl/sim/pdf/sim52_pdf/Rogowski.pdf

Rogowski M (2018a) Use of Monitoring System of tourist traffic (MSTT) in Stolowe Mts National Park for Visitors description. Economics and Environment 65: 87-98. http://www.ekonomiaisrodowisko.pl/uploads/Ei\%C $5 \% 9 A \% 2$ 065/07_rogowski.pdf

Rogowski M (2018b) Spatiotemporal distribution of visitors on the summit of Śnieżka in 2015. Geographical Studies 154: 107125. https://doi.org/10.4467/20833113PG.18.011.9443

Rogowski M (2019) Assessing the tourism carrying capacity of hiking trails in the Szczeliniec Wielki and Błedne Skały in Stołowe Mts National Park. Forest Research Papers 80(2): 125-135. https://doi.org/10.2478/frp-2019-0011

Ross J (2005) Visitor counters in parks: management practice for counter calibration. Department of Conservation, Wellington, New Zealand.

http://www.rockies.ca/files/reports/Visitor\%20Monitoring\% 20Program_fish\%20Creek\%20Provincial\%2oPark.pdf

Rota JJ, Pérez M, Serrano Y, Giné AD (2019) Visitor monitoring in protected areas: an approach to Natura 2000 sites using Volunteered Geographic Information (VGI). Geografisk Tidsskrift-Danish Journal of Geography 119(1): 69-83. https://doi.org/10.1080/00167223.2019.1573409

Russo AP (2002) The "vicious circle" of tourism development in heritage cities. Annals of Tourism Research 20(1): 165-182. https://doi.org/10.1016/So160-7383(01)00029-9

Schreyer R, Roggenbuck JW (1978) The influence of experience expectations on crowding perceptions and social psychological carrying capacities. Leisure Sciences 1(4): 373394. https://doi.org/10.1080/01490407809512896

Shoval N, and Isaacson M (2010) Tourist mobility and advanced tracking technologies New York: Routledge.

Simmonds C, McGivney A, Reilly P, et al. (2018) Crisis in our national parks: how tourists are loving nature to death. https://wwwtheguardiancom/environment/2018/nov/20/na tional-parks-america-overcrowding-crisis-tourism-visitationsolutions; accessed on 2019-09-25

Sitarz M, Bukowski M, Zięba S, Zwijacz-Kozica T (2018) Monitoring of illegal human activities in the Tatra National Park, Poland. The 9th International Conference on Monitoring and Management of Visitors in Recreational and Protected Areas (MMV9), Abstract Book, 29-31 August 2018, Bordeaux, France. https://mmv9.sciencesconf.org/data/ pages/last_version_abstract_book_7.pdf)

Stasiak A (2007) Tourism in national park - areas of conflict. Turyzm/Tourism 7(2): 5-24. http://dspace.uni.lodz.pl:8080/ xmlui/bitstream/handle/11089/28094/Turyzm_1997_2_Sta siak.pdf? sequence $=1$ \&isAllowed $=\mathrm{y}$

Svajda J (2009) Contribution for Improvement of Visitor Monitoring in the Tatra National Park. Ecomont 1(2): 13-18. https://doi.org/10.1553/ecomont2s13

Taczanowska K, Gonzalez LM, Garcia-Masso X, et al. (2014) Evaluating the structure and use of hiking trails in recreational areas using a mixed GPS tracking and graph theory approach. Applied Geography 55: 184-192. https://doi.org/10.1016/j.apgeog.2014.09.011

Thornton P, Williams A, and Shaw G (1997) Revisiting timespace diaries: anexploratory case study of tourist behaviour in Cornwall. England Environment and Planning 29: 1847-1868.

Watson AE, Cole DN, Turner DL, and Reynolds PS (2000) Wilderness recreation use estimation: a handbook of methods and systems. Rocky Mountain Research Station, Forest Service, US Department of Agriculture. https://www.fs.fed.us/rm/pubs/rmrs_gtro56.pdf

Wolf ID, Hagenloh G, Croft DB (2012) Visitor monitoring along roads and hiking trails: How to determine usage levels in tourist sites. Tourism Management 33: 16-28.

https://doi.org/10.1016/j.tourman.2011.01.019 